\title{
A SOURCE OF ERROR IN SERUM GLUTAMIC- OXALOACETIC TRANSAMINASE DETERMINATION
}

\author{
BY \\ S. B. ROSALKI AND J. H. WILKINSON \\ From the Department of Chemical Pathology, Westminster Medical School, London
}

(RECEIVED FOR PUBLICATION OCTOBER 28, 1958)

In the summer of 1958 we observed that the results of serum glutamic-oxaloacetic transaminase (SGO - T) determinations by the spectrophotometric method of Karmen, Wróblewski, and LaDue (1955) appeared to be appreciably higher than during previous months. This suspicion was confirmed when the sera from three out of six healthy young adults were found to give SGO-T values greater than 40 units per $\mathrm{ml}$., the upper limit of the normal range found in these laboratories by Pryse-Davies and Wilkinson (1958). No increase during this period was noticed in the range of serum glutamic-pyruvic transaminase (SGP-T) figures determined by the similar method of Wróblewski and LaDue (1956).

The spectrophotometric SGO-T and SGP-T methods are based respectively on the following pairs of reactions :

$\left\{\begin{array}{c}\text { aspartic acid }+\alpha \text {-oxoglutaric acid } \stackrel{\text { SGO-T }}{\text { acid }+ \text { glutamic acid }} \rightarrow \text { oxaloacetic } \\ \text { oxaloacetic acid }+\begin{array}{r}\text { D.P.N.H. malic dehydrogenase } \\ \text { acid }+ \text { D.P.N. }\end{array}\end{array}\right.$

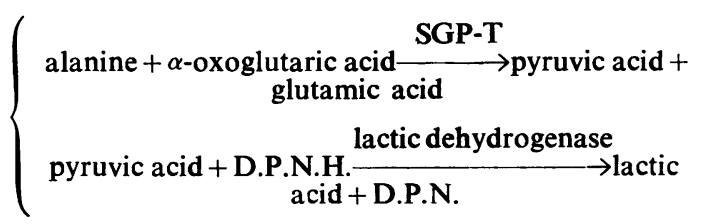

In each case the transaminase activity is proportional to the rate of oxidation of reduced diphosphopyridine nucleotide (D.P.N.H.), the destruction of which is followed by observing the fall in optical density at $340 \mathrm{~m} \mu$.

\section{Impurity of Malic Dehydrogenase}

The increase in SGO-T figures appeared to coincide with the introduction of a new batch of malic dehydrogenase (M.D.H. 1), but this enzyme did not effect transamination in the absence of serum and hence did not appear to be contaminated with a transaminase. The explanation of the anomaly, however, was obtained from studies with pyridoxal 5-phosphate which is known to function as a coenzyme in transamination reactions (Lichstein, Gunsalus, and Umbreit, 1945). Considerable transaminase activity was demonstrated when $0.2 \mathrm{ml}$. of a solution containing $0.2 \mu \mathrm{g}$. pyridoxal 5-phosphate replaced the $0.2 \mathrm{ml}$. of serum normally used in the SGO-T test. Moreover, the combination of M.D.H. 1 and pyridoxal 5-phosphate was shown to effect transamination between aspartic acid and $\alpha$-oxoglutaric acid, the formation of glutamic and oxaloacetic acids being demonstrated by paper chromatography. Neither M.D.H. 1 alone nor pyridoxal 5-phosphate alone could produce this transamination, nor were pyridoxine hydrochloride or pyridoxamine dihydrochloride able to replace pyridoxal 5-phosphate.

These results suggested that pyridoxal 5-phosphate activated a glutamic-oxaloacetic apo-transaminase contaminating M.D.H. 1. Malic dehydrogenase is obtained commercially from heart muscle, a tissue rich in glutamicoxaloacetic transaminase, and it is likely that the end-product might be contaminated by the corresponding apo-transaminase, the coenzyme having been removed during purification. The presence of the contaminating apo-transaminase would remain undetected until the addition of pyridoxal 5-phosphate.

Adding pyridoxal 5-phosphate to lactic dehydrogenase (the enzyme used for SGP-T determination) showed that it too contained glutamic-oxaloacetic apo-transaminase but in a much smaller amount than M.D.H. 1. Lactic dehydrogenase is prepared from skeletal muscle, a tissue which contains glutamic-oxaloacetic transaminase but does not contain a significant amount of glutamic-pyruvic transaminase. Contamination with glutamic-oxaloacetic apotransaminase and freedom from contamination 
with glutamic-pyruvic apo-transaminase is therefore to be expected, and this would explain our inability to demonstrate an effect of pyridoxal 5-phosphate on the glutamic-pyruvic transaminase system.

A second sample of malic dehydrogenase (M.D.H. 2) obtained from a different supplier showed no transaminase activity when pyridoxal 5-phosphate was added in 10 times the concentration previously found to activate M.D.H. 1 . Parallel SGO-T determinations were made on a number of sera using both batches of malic dehydrogenase, and the results were consistently 5-10 units lower with the new sample. Varying the concentration of M.D.H. 2 did not affect the SGO-T activity of sera, but similar alterations in the concentration of M.D.H. 1 caused appreciable changes in the apparent SGO-T figures. It may therefore be concluded that the high results obtained with M.D.H. 1 were due to its contamination with a glutamic-oxaloacetic apo-transaminase activated by pyridoxal present in serum.

Experiments with pyridoxal 5-phosphate indicated that the discrepancy between the SGO-T values obtained using the malic dehydrogenases from the different suppliers could be accounted for by assuming a serum pyridoxal 5-phosphate level of between 10 and $100 \mu \mathrm{g}$. per $100 \mathrm{ml}$.

\section{Conclusions}

It is recommended that batches of malic dehydrogenase intended for SGO-T determination should not only be tested for possible transaminase contamination using a blank containing malic dehydrogenase and omitting serum, but also for apo-transaminase content using a blank containing pyridoxal 5-phosphate in place of serum. Alternatively new supplies of malic dehydrogenase may be compared with a batch known to give satisfactory results by carrying out parallel SGO-T determinations on a number of different sera, the method used during the course of the study by Pryse-Davies and Wilkinson (1958).

It is further suggested that the activation by pyridoxal 5-phosphate of the glutamicoxaloacetic apo-transaminase contaminating certain preparations of malic dehydrogenase might form the basis of a method for the determination of pyridoxal.

\section{Summary}

Erroneously high serum glutamic-oxaloacetic transaminase (SGO-T) levels determined by the spectrophotometric method were found to be due to the presence of an apo-transaminase in the malic dehydrogenase used.

It is recommended that each batch of malic dehydrogenase should be tested for the presence of this apo-transaminase by carrying out blank determinations in which serum is replaced by pyridoxal 5-phosphate.

The possibility of using samples of malic dehydrogenase containing apo-transaminase as a means of determining pyridoxal is suggested.

We wish to thank Dr. J. Pryse-Davies for his helpful comments, and the Central Research Fund of the University of London for a grant (to J. H. W.) for the purchase of the spectrophotometer used during this work.

\section{REFERENCES}

Karmen, A., Wróblewski, F., and LaDue, J. S. (1955). J. clin. Invest . $34,126$.

Lichstein, H. C., Gunsalus, I. C., and Umbreit, W. W. (1945). J. biol. Chem. 161, 311.

Pryse-Davies, J., and Wilkinson, J. H. (1958). Lancet, 1, 1249.

Wróblewski, F., and LaDue, J. S. (1956). Proc. Soc. exp. Biol. (N.Y.), 91, 569 . 